\title{
Leading by example: Exploring the influence of design examples on children's creative ideation
}

\author{
Laura Benton (corresponding author) ${ }^{1}$, l.benton@ucl.ac.uk; George Varotsis ${ }^{2}$, \\ gvarotsis@gmail.com; Asimina Vasalou', a.vasalou@ucl.ac.uk \\ ${ }^{1}$ UCL Knowledge Lab, UCL Institute of Education, 23-29 Emerald Street, London, WC1N \\ $3 \mathrm{QS}$
}

${ }^{2}$ GSM London, Meridian House, Royal Hill, London, SE10 8RD

\begin{abstract}
Creative ideation is integral to the design process; to be considered creative an idea must be deemed both novel and appropriate. Design examples are often provided to inspire creativity but may also constrain designers' imaginations (design fixation), a phenomenon observed during children's ideation in participatory design (PD). This paper addresses a gap in the literature by empirically investigating this phenomenon through an exploratory case study of two game narrative design workshops involving 37 children. Children's design ideas from these workshops were systematically coded by two researchers following a deductive content analysis approach and inter-rater reliability was established. Our findings show that utilising design examples can ensure appropriateness (i.e. narrative relevance and coherence), and albeit some design fixation more often facilitates the creative process by enabling existing ideas to be recycled and combined with novel ideas. This research contributes potential methodological adaptations to better foster children's creativity during PD.
\end{abstract}

\section{Keywords}

Creative design; creativity; participatory design; children; games design; narrative

\section{Introduction}

Creativity has traditionally been considered an integral part of ideation during the design process, regardless of the domain, with designers "required to be creative if they are to arrive at new and useful solutions to the problems that they address" (Crilly and Cardoso, 2017). An idea is considered creative if it is not only novel but also appropriate to the design problem 
context (Warr and O'Neill, 2005). Within the domain of technology design new participatory approaches to design have been developed in an effort to increase the appropriateness of the resulting technology. Design approaches, such a participatory design (PD), involve the participation of representatives of the target end user group (Bossen et al., 2012; Schuler and Namioka, 1993). Within a PD team each member is viewed as an expert (with respect to their individual background, perspective, knowledge) who is expected to collaboratively engage in creative ideation and design decision-making (Sanoff, 2007); with the participant's role shifted from a recipient of the design output to an "engaged design decision-maker" (Luck, 2007). Sanders and Stappers (2008) highlight how this alters the designer's role during this process to that of facilitator, in order to lead, guide and provide "scaffolds as well as clean slates to encourage people at all levels of creativity".

In the late 1990s, researchers began to involve child participants in the design of technology using adapted PD methods and techniques (Druin, 1999). Since then children have been involved in the design of a wide range of different technologies spanning from storytelling tools (Alborzi et al., 2000) and educational tutoring systems (Grawemeyer et al., 2012) to augmented reality artefacts (Cassidy et al., 2015) and organic user interfaces (e.g. interfaces that can take the form of clothing or wallpaper) (Read et al., 2013a). Reflecting on her experiences with children acting as co-designers, Druin (1999) suggests that 7-10 year old children are the most effective age group to work with. This is because of their more developed verbal and reflective skills as well as understanding of more abstract ideas, but not yet being "too heavily burdened with pre-conceived notions of the way things 'are supposed to be" as older children can be. This is seen as a valuable asset to the design process, with children often being involved for their potential to generate original and innovative design ideas that adults would not be able to conceive. Albeit this recognition of children's creativity, Kuure et al. (2010) point out that during PD children frequently reuse or 'recycle' ideas taken from their existing knowledge or previous experiences.

Early in the PD process it is common for adults to share with children some background information about the problem space in which the technology they are designing sits; this may include prompts such as design examples. These examples are often used to help make a complex concept more understandable and concrete, to provide initial inspiration or an opportunity for reinterpretation on which the children can build their own ideas, or to guide the direction of the idea generation, for example by providing a visual framework (Benton and Johnson, 2014; Herring et al., 2009; Read et al., 2013a). However, as Read et al. (2013a) observe, children are quick to adopt these given design examples and can subsequently find it difficult to engage in divergent thinking, i.e. to go beyond these examples. This results in the same or similar designer-led ideas repeatedly occurring throughout the design process, 
undermining one of the aspired outcomes of PD - to empower the users and also to facilitate collective creativity amongst the participants.

While the use of concrete design examples is seen as an important and facilitative part of the PD process (Alborzi et al., 2000; Benton and Johnson, 2014; Read et al., 2013a), little attention has been given to the exact form and impact of these design examples within the child PD literature. Drawing attention to this gap, Kuure et al. (2010) propose that designers should be more conscious about this challenging aspect of the design process, engaging in methodological development that considers how these examples can be best used to support children's creativity in relation to the design at hand.

Acknowledging this challenge, this paper presents an exploratory case study that examines the influence of design examples on children's ideation during the design of a game narrative. Child PD researchers have begun to acknowledge the potential (both positive and negative) impact that design examples may have on children's creativity and resulting outcomes of the PD process, but the extent to which these examples permeate children's ideation process has not yet been explored in any systematic way. This is an important focus of research because it evolves our understanding of the relationship between design examples and children's creativity, indicating potential opportunities for how we can more effectively utilise these examples to facilitate children's creative ideation process during PD. We present these opportunities as a set of methodological recommendation for child-computer interaction (CCI) researchers and designers as the primary contribution of this paper.

In the following section, we review how participant creativity has been theorised in previous work, and identify the challenges involved in fostering it, to motivate the case for the empirical examination of children's ideation during the PD process. We go on to contextualise the main characteristics of creativity in game narrative construction, which is the focus of our case study.

\section{Related Literature}

\subsection{PD, Creativity and Design Examples}

It has been previously argued that creativity during the design process can increase the probability of the design outcome being both useful and usable (Warr and O'Neill, 2005). Design researchers have defined creative ideas along several dimensions. Warr and O'Neill (2005) consider a design idea to be creative "if it is new or unusual to the mind in which it arose (novelty) and conforms to the requirements of the design problem (appropriateness)". Similarly, other researchers have highlighted the importance of novelty as well as desired 
utility, appropriateness or value to the field within which it is applied to (Beghetto, 2005; Runco and Jaeger, 2012; Shah et al., 2003; Sternberg and Lubart, 1999; Wyse and Ferrari, 2015). Some definitions additionally include that the idea should be non-obvious or surprising in some way (Crilly and Cardoso, 2017; Howard et al., 2008). Furthermore Vernon (1989) extends this definition to incorporate the judgment of experts i.e. to be recognised as creative by the field (Wyse and Ferrari, 2015).

Idea novelty and appropriateness are outcomes of both divergent and convergent thinking (Farooq et al., 2005), where individuals initially generate a set of novel design ideas (divergent thinking) and then narrow these ideas down to one that is appropriate to the design constraints (convergent thinking). Design examples have been argued to serve "a large and critical role" in fostering this process of creative thinking (Herring et al., 2009). For example, the use of design examples during the design process is intended to "enhance the flow of useful ideas" (Smith et al., 1993). Design examples can include demonstrating or showing similar existing design artefacts e.g. a computer game or web page, or could be embedded within a fictional scenario which introduces the use of an imagined app or interface (Benton and Johnson, 2014; Herring et al., 2009; Hiniker et al., 2017; Read et al., 2013a).

More experienced designers typically draw on their prior experience which can help guide them in exploring and developing ideas into creative products (Smith et al., 1993). However, this is often not possible for novice designers, such as children. For instance, in designing a conflict resolution game with children Khaled and Vasalou (2014) report that when the designers did not include design examples children relied on their previous experiences of games and introduced familiar conflict actions that were either not novel or not appropriate to the design task. In a later workshop which did include design examples, the examples acted as scaffolds for more novel ideas that were also relevant to the educational objectives of the game. Furthermore the inclusion of design examples can be imperative for children who would otherwise be unable or face severe challenges to be able to participate within the design process (Benton et al., 2011; Hornof, 2009), for instance by providing scaffolding for children with autism who may struggle with the more abstract aspects of the creative process (Low et al., 2009).

\subsection{Inspiration, Fixation and Recycling of Ideas}

Although design examples can provide valuable sources of inspiration or information about the design problem during the ideation process concerns have also been raised about the potential constraints on creativity that the use of these examples may place. This phenomenon is commonly referred to as design fixation (Crilly and Cardoso, 2017). Crilly and Cardoso (2017) define design fixation as "a state in which someone engaged in a design task 
undertakes a restricted exploration of the design space due to an unconscious bias resulting from prior experiences, knowledge or assumptions". Fixation is often (but not always) seen as a negative phenomenon related to a form of idea repetition, bias or oversight, the reduction of which unlocks creative potential (Crilly and Cardoso, 2017; Vasconcelos and Crilly, 2016). Design fixation also appears to be at odds with the definition of creativity in terms of the requirement for a creative idea to be novel and extend beyond the obvious or norm within the domain.

Typically the PD literature highlights the importance of children being able to contribute novel design ideas (Kelly et al., 2006; Mazzone et al., 2007; Sluis-Thiescheffer et al., 2007). Read et al. (2010) also acknowledge the importance of design examples in enabling children, particularly younger children, to understand more complex abstract design scenarios.

However, in later work Read et al. (2013a) highlight the problem of 'bias' (i.e. design fixation) from the use of such design examples, preventing children from thinking divergently later in the design process. Furthermore Hiniker et al. (2017) found that the children they worked with "incorporated literal details from the materials we used and from facilitators' comments, regardless of their relevance", framing the influence of these example ideas as a 'limitation'. Potential solutions have been proposed to overcome this issue, either by adapting the design method to introduce the design task in a more ambiguous way which conveys salient design features but leaves the design space more open (Read et al., 2013a) or taking into account the possible influence of the design examples when interpreting the resulting design solutions (Hiniker et al., 2017).

However, as Sio et al. (2015) argue, the copying of existing ideas can demonstrate a narrower, but deeper exploration of the design space, with this deep exploration potentially leading to the generation of high novelty and quality ideas. In the context of child PD, Kuure et al. (2010) refer to this phenomenon as 'recycling' which they define as the reuse of another's work in "exact or processed form" and highlight that researchers should not solely consider the recycling of others' ideas as a negative outcome. Creativity may be viewed in the context of both what the individual participant brings and social learning (Pentland, 2014), i.e. it is important to build on what others have done but to avoid group think by falling into one prevailing pattern. Therefore, it is necessary to explore how and where children's ideation is influenced, as well as how the form and process of introducing design examples could be evolved to inspire and guide without constraining creativity.

Purcell and Gero (1992) suggest that the extent of influence can vary in part on the familiarity of the participant with the design task and their level of design expertise, which in the case of children would be typically be very limited. Furthermore it is possible the cognitive effort of 
the design task may make it challenging for participants to think divergently (Crilly and Cardoso, 2017) which would increase the likelihood of reliance on the design examples.

Design fixation has been most extensively investigated under experimental conditions within the field of engineering design (Crilly and Cardoso, 2017) and although it has been acknowledged as an issue within interaction design (Hassard et al., 2009) there was been limited work exploring the impact of design fixation within PD involving children.

\subsection{Motivation and Research Questions}

Creativity is imperative to ensuring the resulting output of the design process is fit for purpose, with creative ideas defined along the dimensions of appropriateness and novelty, which may be judged by experts within the domain. An idea can be appropriate but not novel and vice versa - a creative idea fulfils both criteria. Design examples can act as a facilitative mechanism to creative ideation, particularly in structuring the appropriateness aspect of creativity and guiding convergent thinking, but can also restrict the design space constraining novelty and divergent thinking. As our review of the literature highlights the design community has been divided on whether the reuse of design examples is favourable. Participants could become fixated on the design examples in a such a way that the resulting design outcome repeats the same underlying idea with only surface changes, or participants could recycle elements from these examples and subsequently combine these with their own novel ideas. The goal of this research is to investigate children's creative ideation within the context of PD - looking at how design examples can influence both the appropriateness and novelty of their ideas. The specific research questions that guide our work are:

RQ1: To what extent do children generate appropriate design ideas and what are the barriers to facilitating appropriateness within PD?

RQ2: What is the form and prevalence of design example reuse during the PD process and what is its impact on creative ideation?

Within this paper we investigate these research questions through a case study focused on the ideation process of designed game narratives by children, introduced next.

\section{Case Study}

\subsection{Creative ideation for game narratives}

One of the defining features of games is their narrative (Winn, 2008) and incorporating storylines into games is a common technique for promoting engagement within learning games, providing a scaffold for children's meaning-making (Tan et al., 2011). Game scholars 
recognize that game narratives are both designed and constructed through play (Calleja, 2013). Focusing on designed narrative that is often the focus of PD, the basis of narrative is formed through an intricate connection of different narrative or story elements, i.e. characters and their actions based on their motivations and dramatic needs, the events caused as a result of such actions, the actions instigated from other characters in reciprocation, temporal and spatial dimensions of the story, and the causality stemming from these interactions etc. (Branigan, 2013). As part of this the who (fictional characters), what (the dramatic goal -i.e. what the story is about), why (causal and motivation justification of actions) and how (dialogue and action) are cornerstone assumptions that have to be justified so that a coherence exists within the narrative (Varotsis, 2015), without evident gaps (plot holes) appearing in the narrative logic.

Mental representations and referential systems are paramount to the creation of stories, providing a structure for the narrative elements discussed above. These are acquired by professional authors through researching the topic under question. This can be partly mitigated by the provision of narrative examples providing a referential system which demonstrates an appropriate narrative structure (of how to ensure a story is (i) relevant in terms of the requirements of the design problem and (ii) communicated in a coherent way to the audience) as well as providing a basis for inspiring novel ideas in line with the creative focus of PD (by encouraging children to draw on their imagination). In previous research which has specifically focused on the use of PD for game design with children these referential systems have been provided through the specific choice of environment in which the design session is undertaken e.g. conducting sessions in children's homes for designing a game about avoiding domestic accidents (Giaccardi et al., 2012) or being provided with a series of images related to the game theme, and then noting down related "thoughts, associations and feelings" (Duh et al., 2010).

Our review of the literature therefore suggests that within the specific context of narrative generation in order for a design idea to be considered creative, in addition to the novelty of the idea, its appropriateness to the design space includes not only relevance to the genre of the game but also its coherence.

\subsection{Day of the Dead narrative}

The case study research formed part of a research project aiming to develop a learning game to support the progression of reading of 9-11 year old struggling readers. A participatory approach was taken throughout the project involving teachers and parents as well as children in the design process by employing PD methods and techniques. 
In terms of its design, the learning game was envisioned to present a series of interactive mini-games on literacy, linked together through a common narrative. The topic of this narrative focused around the Mexican festival Día de Muertos, also known as the 'Day of the Dead' (DotD), and was initially proposed by the game designer of the project. The DotD is an annual event that takes place across Mexico during which people celebrate the lives of friends and family who have died. The core message of DotD is of remembrance and acceptance of death, with death being viewed as a continuation of life. The designers initially became interested in DotD because of its aesthetics. On further exploration of what the festival signified, particularly, reflecting on the central role of communication in DotD, they decided to draw on it to enhance struggling readers' self-esteem by placing them in a heroic role within the world.

The main game narrative would begin with the player discovering that the world of the dead needs the help of the living in order for their world to continue existing (the why). As children progressed within the game, they would discover new stories about the relationship between living and dead characters (i.e. the who). Additionally, the player finds herself gifted with the extraordinary skill of being able to see, hear, and talk to the dead (the how). It is therefore up to the player to help save the world of the dead (the what).

In advancing our design work on game narrative, we recognised the potentially challenging and sensitive nature of this design concept for our target age group, which could prompt some children to reflect on their own attitudes towards mortality and ideas about life after death. Additionally, in considering the design of game narratives more broadly, children and adults may understand these narratives differently due to their previously acquired schemata (Duh et al., 2010). Even very young children are able to comprehend narrative structures, and involving the children in the narrative design could ensure the resulting game is "contextually, temporally and culturally relevant to their life experiences" (Duh et al., 2010). Therefore in light of our participatory approach and our desire to design something appropriate and appealing to our target user group we decided to involve the children themselves within the game narrative design.

\subsection{Description of Design Workshops}

\subsubsection{Participants}

We undertook two design workshops with two classes (year five and six) at a mainstream primary school in London, England. The school was located in a socially and ethnically diverse area with a higher than average proportion of students whose first language was not English. The children were all within the target age group (ages 9-11) for the learning game. 
A total of 37 children participated (20 boys and 17 girls), with 22 children within the year five class (aged 9-10) and 15 children within the year six class (aged 10-11). The children were divided into teams of four or five by their teacher, with a total of five teams in the year five class and four teams in the year six class.

\subsubsection{Workshop Structure}

Each design workshop lasted approximately an hour and was led by three to four researchers. The researchers acted as 'facilitators' (in line with that proposed by (Vaajakallio et al., 2009)) and worked in a more child-centred way moving between teams during the workshops rather than working directly with the children as equal design partners on a single design team (as in (Druin, 2002)). The facilitator role involved presenting the design task to the whole class and explaining the children's design role, i.e. to propose ideas for game characters and narrative. The researchers also ensured the children understood and stayed on task, managed interpersonal difficulties as well as prompted the children with questions about their ideas to help them in expanding and presenting back their narratives, but did not contribute their own ideas.

The workshop involved a series of four activities that guided children to express, develop and document stories for the DotD game narrative. These activities were inspired by several existing storytelling-based PD techniques, which included presenting the design context through a story (Dindler and Iversen, 2007), the use of art-based materials to aid initial story character generation (Alborzi et al., 2000), documenting initial story ideas through storyboards (Moraveji et al., 2007) and performing final stories using video cameras (Giaccardi et al., 2012).

\subsubsection{Design Examples}

The researchers presented the design context of the DotD festival through two separate design examples at the start of the workshop:

- Design Example 1 - the first example was presented through the medium of animated film. The story was depicted solely through moving image and music, there was no verbal narrative or speech. The story was centred around the experience of a young girl who had lost her mother. The girl visited her mother's grave on the day of the festival and was feeling sad. She was then pulled down into the world of the dead and led around different DotD celebrations by a 'calacas' (skeleton wearing human clothes) who was later revealed to be her mother. She returned to the world of the living with a marigold flower her mother gave her, which helps her overcome her sadness. 
- Design Example 2 - the second example was presented through the medium of speech, images and text. The story was verbally narrated by a researcher and illustrated using a series of photos and images of the festival. The story centred around a young girl whose pet dog had recently died. The girl was feeling regretful that she had not been able to express her love for her dog and so was told about the customs and traditions of the DotD by a friend as a way to contact him. She was then able to try out some of these herself to communicate her feelings to the world of the dead. Further details were also provided about each of the two characters within the design example including their hobbies/interests, favourite quotes and job (see Figure 1), which also served to introduce the children to their narrative design task.

\section{CREATE YOUR CHARACTERS}
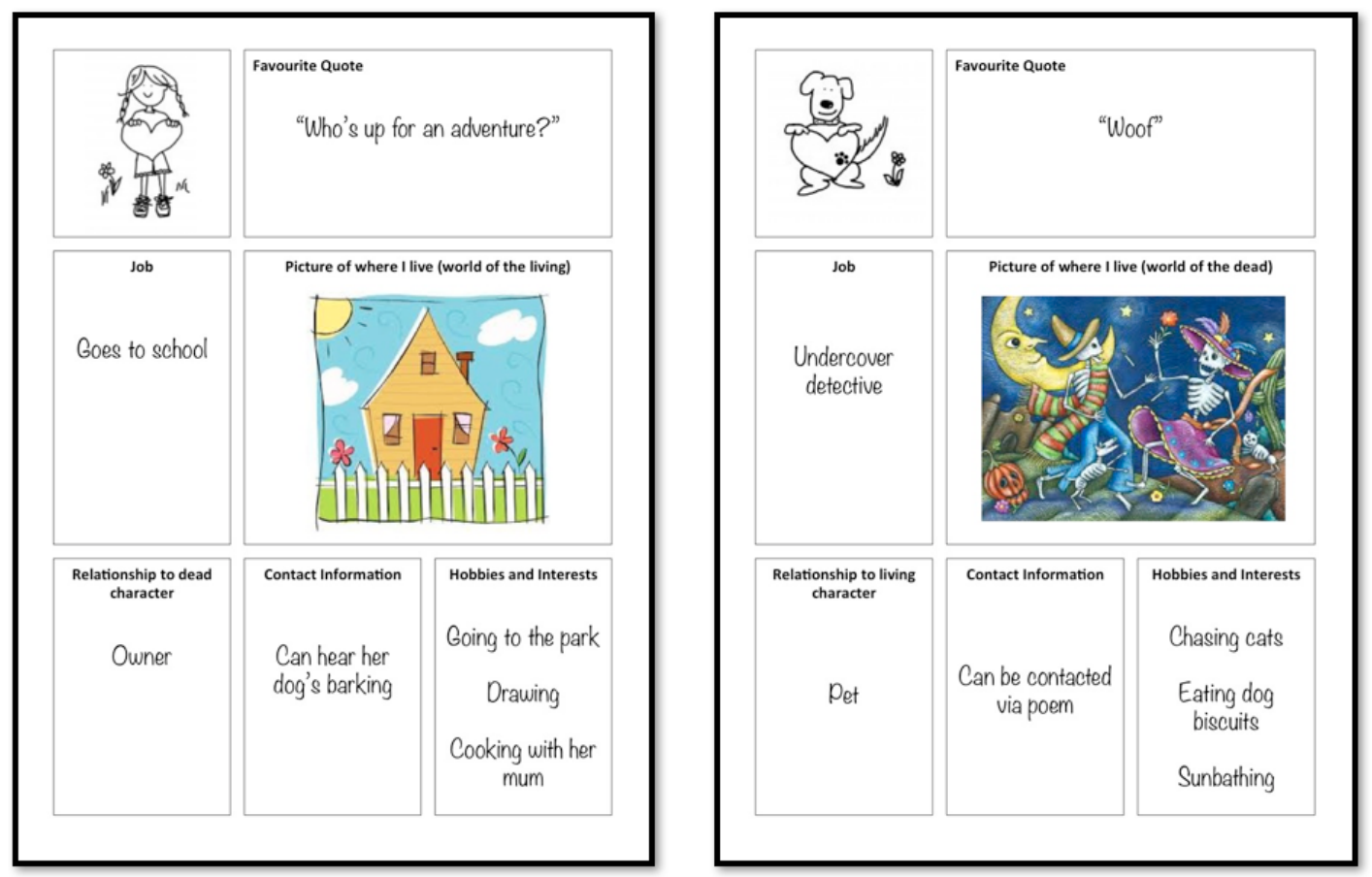

Figure 1 - Further information provided about story characters in Design Example 2 also used in children's narrative game design task

\subsubsection{Design Task}

After the design examples had been provided the children were given blank versions of the character paper templates (from Figure 1) to help them generate ideas for their own characters. They were also given modelling clay as well as a selection of other art materials and asked to build or draw each of their characters (the who). Next the children were asked to create a story about their characters. In supporting them to develop stories that described 
relationships between characters over time, they were asked questions which were intended to encourage them to consider the following:

- The nature of the relationships between the living and the dead (the what)

- The motivation for the living and the dead to communicate (the why)

- The means of communication (the how)

Each team was provided with a blank paper storyboard on which they could document their ideas for their story. Lastly each team was given a Flip video camera and asked to capture their story on it to enable the researchers to share the children's story ideas with the game development team.

\subsection{Data Collection and Narrative Analysis}

To capture the children's narrative construction, during the workshop researchers took written field notes at a team-level and compiled these notes into full written accounts of what happened within each team after the workshop had ended. The intention of the researchers was to capture each team's unfolding narrative as well as include finer details, e.g. character backstories, that would help support the interpretation of the narrative performances within the videos. Photographs of the design artifacts children produced to support the communication of their narrative were also taken during the workshop (e.g. see Figure 2) and the videos recorded by the children which shared the final account of their narrative were transcribed. Triangulation between the field notes, design artifacts and videos enabled us to build a more detailed and complete picture of each team's narrative. 

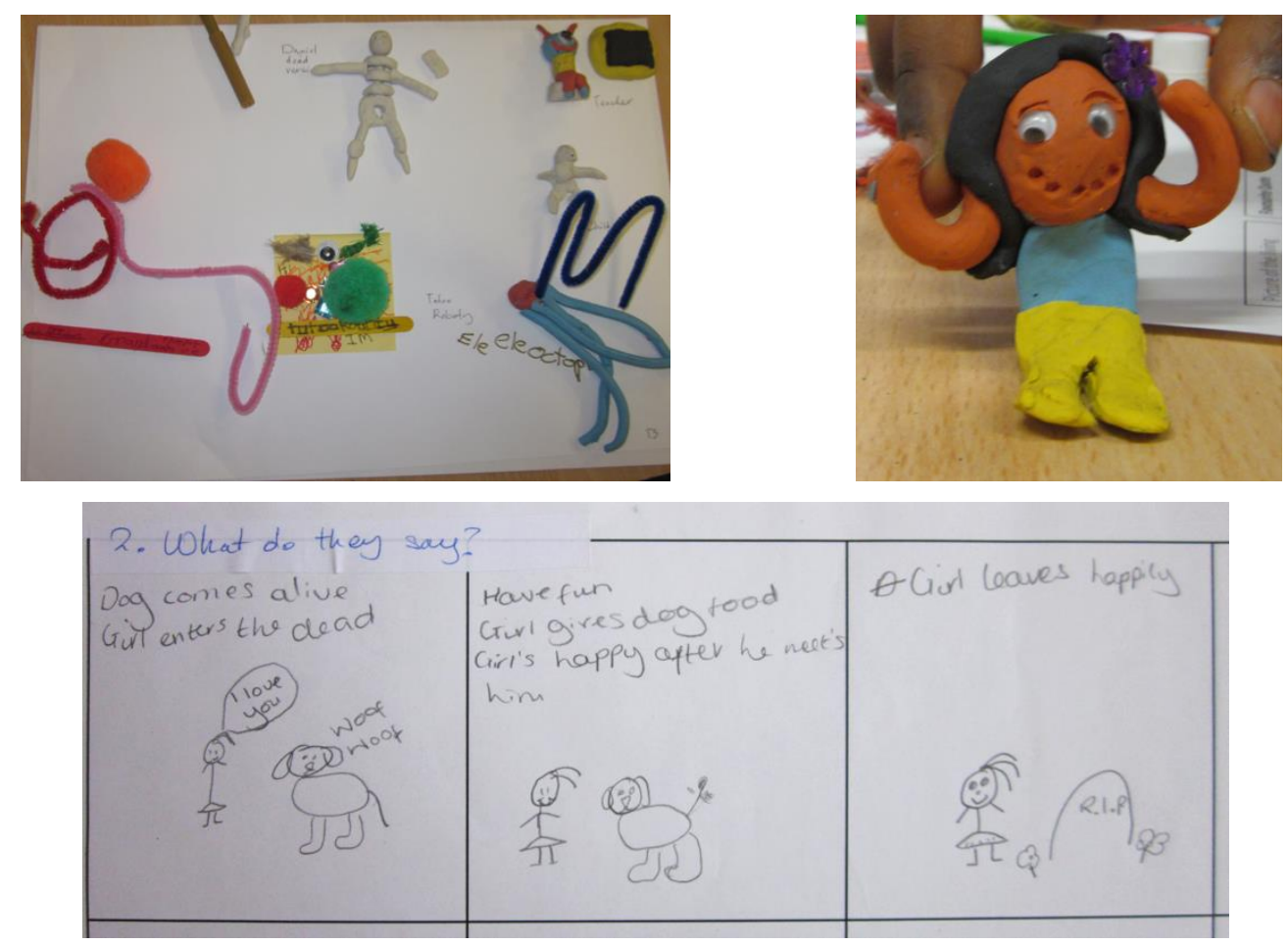

Figure 2 - Examples of the design artifacts that the children produced during the workshop

Given the complexity of children's game narrative ideas, and the multiplicity of possible interpretations, we created a systematic and rigorous approach to understand novelty and appropriateness (relevance and coherence). To achieve this we analysed each idea's representation of the four narrative dimensions (who, what, why and how) following a deductive content analysis approach (Hsieh and Shannon, 2005) based on the narrative theory presented in section 4.1 (Varotsis, 2015). Our priori coding framework based around the cornerstone assumptions of narrative logic included the following four dimensions:

- Who - the living and dead characters included in the narratives

- What - the goal of the living character, e.g. to communicate with the dead character

- Why - the reason that the living character wants to communicate with the dead character

- How - the dialogue and action that occurs as the characters seek to achieve their communication goal

The use of content analysis enabled us to quantify patterns within the narratives as well as describe these patterns in a qualitative manner (Vaismoradi et al., 2013). We firstly systematically coded the two design examples used at the start of the workshop (see Section 3.3.3) to characterise the specific example ideas for each of the four dimensions. Next, each of the game narratives generated by the groups within the two workshops were translated into this framework (for an excerpt of the outcome of this process see Table 1) and two researchers (one researcher who had been involved in running the workshops and an independent researcher who had expertise in narrative theory) coded children's ideas 
separately. One of the teams (of four children) had been unable to come to a consensus about their final story, which led to the participants in this team generating their own individual narratives. Since our data collection and subsequent analysis was performed on a team-level, the data for this team was excluded from the analysis resulting in the analysis of a total of eight team game narratives.

The two coders firstly analysed each narrative dimension in terms of its relevance to the original design task. An idea was coded as relevant if the narrative dimension met one of the following criteria:

- one living and one dead character (Who)

- one character was trying to communicate with the other (What)

- a reason was provided for this communication (Why)

- any related dialogue and action was undertaken to motivate or achieve this communication (How)

The coherence of the team's ideas was considered at a narrative-level and the overall narrative was coded as coherent if it incorporated at least one idea that fulfilled each of the above dimensions (who, what, why, how) forming the cornerstones of narrative logic.

Lastly the coders considered the novelty of the ideas for each dimension by comparing each of the team's ideas to the ideas within the two design example narratives. As previously posited, a creative idea is one that fulfils both appropriateness (in this context both relevant and coherent) and novelty. Thus, if a game narrative had been previously considered not to fulfil appropriateness, the coders did not assess its novelty. Based on our earlier review of the design ideation literature (see Section 2.2) we coded children's ideas using three characterisations of idea generation:

- Fixate - a direct copy of an example idea or with only minor adjustments e.g. the dead character being a $\operatorname{dog}$ (as in Design Example 2) with a different name

- Recycle - reuse of elements of an example idea combined with some novel elements e.g. the living character tries to make contact with the dead character by leaving a marigold trail (from Design Example 2) around a mirror

- Novel - an idea not found in either of the example narratives e.g. the dead character communicates with the living character using a medal

To establish inter-rater reliability we used Cohen's Kappa (Stemler, 2001). After an initial pass this was calculated to bek $=0.36$ (from 121 individual codes) which suggests fair agreement between the two coders. As this initial agreement was only moderate, the coders 
subsequently discussed their coding strategy in order to identify differences in the interpretation and application of the coding framework. These included:

- Coding errors

- A discrepancy between the understanding of the relevance code. Specifically, one coder judging an idea to be relevant in relation to the particular contexts of the design examples instead of the broader context of the high-level design task (i.e. any relationship, motivation and means of communication between any living and dead character)

- Overlooking certain parts of the narrative (one coder was less familiar with the stories having not participated in the workshops)

- Not considering narrative elements as novel, e.g. sub-plots

After further clarifying the coding framework, both coders independently re-coded the data taking into account the above issues and the inter-rater reliability was re-calculated for this second pass as $\kappa=0.76$ which is good agreement. The remaining code discrepancies were discussed between the coders, who then came to an agreement on the final coding. Table 1 provides an example excerpt from this coding process. This example showed high relevance to the design task, as children contextualized all four narrative dimensions to this. The inclusion of all four dimensions also established high coherence. However, three of the four narrative dimensions used ideas from Design Example 2 suggesting overall low novelty. 


\begin{tabular}{|c|c|c|c|}
\hline $\begin{array}{c}\text { Narrative } \\
\text { Dimension }\end{array}$ & Idea & $\begin{array}{c}\text { Relevant to } \\
\text { design task }\end{array}$ & $\begin{array}{c}\text { Fixate/ } \\
\text { Recycle/Novel }\end{array}$ \\
\hline Who & Girl and her dog & Yes & Fixate \\
\hline What & $\begin{array}{c}\text { To get peace of mind that her } \\
\text { dog is happy }\end{array}$ & Yes & Recycle \\
\hline Why & $\begin{array}{c}\text { Because she is sad about him } \\
\text { passing away }\end{array}$ & Yes & Recycle \\
\hline How & $\begin{array}{c}\text { The girl cries over her dog's } \\
\text { grave }\end{array}$ & Yes & Fixate \\
\hline & $\begin{array}{c}\text { She sprinkles marigold flowers } \\
\text { on the grave and a flower pulls } \\
\text { her down into the world of the } \\
\text { dead }\end{array}$ & Yes & Fixate \\
\hline & $\begin{array}{c}\ldots \\
\end{array}$ & $\ldots$ & $\ldots$ \\
\hline
\end{tabular}

Table 1 - Excerpt from the coding framework (showing a subset of ideas from one team)

\section{Results}

\section{RQ1: To what extent do children generate appropriate (i.e. both relevant and coherent)} design ideas and what are the barriers to facilitating appropriateness within PD?

A descriptive analysis of the relevance dimension for children's game narrative ideas appears in Table 2 featuring the number of relevant ideas out of the total number of ideas generated by children per dimension. For example, $0 / 1$ indicates that a team generated one irrelevant idea, 0/0 indicates a missing idea, and 3/9 indicates that only 3 were relevant. As is evident in Table 2, whereas teams were able to generate a maximum of one final idea for the Who, What and Why dimensions, the How dimension generated more divergent thinking and thus multiple ideas were proposed. Narrative coherence was established when all four dimensions of a narrative were expressed through at least one idea (relevant or irrelevant) per dimension.

Our findings show that four design teams (Team 1, Team 2, Team 4 and Team 6) out of the eight fully met the criterion of idea relevance for all the narrative dimensions. These teams generated ideas that were aligned to the original design task across the four narrative dimensions and also produced coherent stories that included relevant ideas for each of the narrative dimensions. However, as our later analysis on novelty in Tables 3 and 4 will show, two of these teams (Team 2 and Team 4) directly copied more of their ideas from the 
examples given by the design researchers than the remaining teams. Thus, the reuse of original example ideas could explain the high incidence of narrative relevance.

\begin{tabular}{|c|c|c|c|c|}
\hline \multirow{2}{*}{ Team } & \multicolumn{4}{|c|}{ No. of Relevant Ideas / Total No. of Ideas } \\
\cline { 2 - 5 } & Who & What & Why & How \\
\hline 1 & $1 / 1$ & $1 / 1$ & $1 / 1$ & $3 / 9$ \\
\hline 2 & $1 / 1$ & $1 / 1$ & $1 / 1$ & $10 / 10$ \\
\hline 3 & $1 / 1$ & $0 / 0$ & $0 / 0$ & $3 / 7$ \\
\hline 4 & $1 / 1$ & $1 / 1$ & $1 / 1$ & $9 / 9$ \\
\hline 5 & $1 / 1$ & $0 / 1$ & $0 / 1$ & $2 / 7$ \\
\hline 6 & $1 / 1$ & $1 / 1$ & $1 / 1$ & $6 / 6$ \\
\hline 7 & $1 / 1$ & $0 / 0$ & $0 / 0$ & $1 / 5$ \\
\hline 8 & $1 / 1$ & $1 / 1$ & $0 / 0$ & $5 / 8$ \\
\hline All teams & $\mathbf{8 / 8}$ & $\mathbf{5 / 8}$ & $\mathbf{4 / 8}$ & $\mathbf{3 9 / 6 1}$ \\
\hline
\end{tabular}

Table 2 - Results for relevance of each generated idea for the four narrative dimensions - note that it was only possible to generate multiple final ideas for the 'How' dimension. The grey rows indicate the teams whose narrative lacked coherence as a result of missing narrative dimensions.

The remaining four design teams (Team 3, Team 5, Team 7 and Team 8) deviated substantially from the original design brief. Team 5's game narrative was coherent, but while they first adapted the characters from Design Example 2 children directed the what away from character engagement to revenge. Adding graphic details about the character's death, this substantial focus on violence rendered their game narrative's relevance to the original design scope weak (this mirrors findings from other PD studies involving children e.g. (Tan et al., 2011)). The relevance of game narratives for the other three teams predominantly suffered from a lack of coherence. Both game narratives were missing a dramatic goal and motivation. As a consequence, their character dialogue and action had a lack of direction without any storyline guidance. This gap may have then made it more challenging for the children to stay on task. Indeed, our observations of children within Team 7 showed a shift in focus on building out their individual characters over incorporating them into a wider narrative. In further examining the weak cohesion in these game narratives, Table 2 clearly shows that many of the teams struggled the most with generating the motivation why for the narrative, with three teams missing this dimension from their story. Goal-oriented motivation is of fundamental importance in narrative as it adds forward momentum and direction to the progression of a story. Real-life individuals strive for the satisfaction of psychological and intellectual needs. It is this interaction that creates societal clashes, which stem from the inclination of humans to seek intentions behind every action (Bordwell, 2008). Thus, the actions of fictional characters must have a causal and motivational justification in order to 
acquire a meaningful capacity rather than appearing as random. However, our findings could be interpreted to suggest that the definition and incorporation of this motivation may be a complex task for children.

\section{RQ2: What is the form and prevalence of design example reuse during the PD process and what is the impact on creative ideation?}

Descriptive analysis reported in Table 3 and 4 shows that four of the teams (Team 1, Team 2, Team 4 and Team 6) developed more comprehensive narratives (i.e. had relevant ideas for each dimension that were subsequently assessed for novelty). Of these teams the majority of children's game narrative ideas for the who, what and why dimensions were recycled from the example ideas given by the design researchers.

Upon examination of the novelty patterns across the four dimensions, our findings show that all of the teams recycled the example ideas for the who dimension with the exception of Team 2 who directly copied the examples engaging in design fixation. Design Example 1 had included a family relationship whereas Design Example 2 included a friendship between a child and pet. Mirroring these kinds of close relationships, the teams all either included characters that had different family relationships or forms of friendships. Since close relationships encompass the most important and common forms of relationship from children's lives it is unsurprising that these would be expressed within their narratives.

Examining the idea novelty patterns across dimensions, we observe that Team 2 predominantly replicated Design Example 2. This team designed the same game narrative characters, presented a recycled game narrative goal (to feel reassured that the girl's dog is happy rather than to saying goodbye as in Design Example 2), and posed a similar motivation to the one of the original characters. Additionally, ideas from Design Example 1 were included such as being pulled into the underworld by a flower and celebrating at the end of the festival. Although this suggests a design fixation previously deemed as problematic (Hiniker et al., 2017; Read et al., 2013a), by contrast the remaining three teams (Team 1, Team 4 and Team 6) who fully developed their game narratives engaged in idea recycling that mixed novel ideas with those embedded in the two examples. For instance, Team 4's game narrative was an adaptation of Design Example 1, presenting a similar motivation of sadness and grief about the death of the other character. It included direct copies of ideas related to the underworld (e.g. being pulled into the world by a flower and being surrounded by skeletons), but with a novel dramatic goal to bring the other character back to the world of the living. Furthermore, it introduced several novel elements such as the Ghostbook (a social media platform) for communication between the living and the dead, and a song that is sung to welcome new arrivals in the underworld. Thus, this idea adaptation ensured higher 
relevance to the initial brief without compromising the emergence of novel ideas mixed with recycled ideas.

\begin{tabular}{|c|c|c|c|}
\hline Team & Who & What & Why \\
\hline 1 & Recycle & Novel & Novel \\
\hline 2 & Fixate & Recycle & Recycle \\
\hline 3 & Recycle & $*$ & $*$ \\
\hline 4 & Recycle & Novel & Recycle \\
\hline 5 & Recycle & $*$ & $*$ \\
\hline 6 & Recycle & Novel & Recycle \\
\hline 7 & Recycle & $*$ & $*$ \\
\hline 8 & Recycle & Recycle & $*$ \\
\hline
\end{tabular}

Table 3 - Novelty of ideas generated for the Who, What and Why constructs. * indicates ideas that were not relevant or missing, and thus were not assessed for novelty.

The recycling of example ideas with novel ideas was particularly evident in the how category which elicited a richer number of ideas allowing us to better understand children's creative ideation process. In developing the dialogue and action of their characters, on average, $38 \%$ of the children's ideas were not relevant to the design brief, followed by $28 \%$ of ideas recycled from the examples, $21 \%$ novel ideas and $13 \%$ copied ideas. Within the context of creativity the generation of irrelevant ideas is part of the divergent thinking process, but these should be filtered out during the convergence of the final narrative, which formed the focus of our analysis - however, it appeared for over a third of these ideas convergence did not happen. Table 4 also highlights that the novelty of the how ideas had a similar pattern to the other dimensions (who, what and why) with a mix of novel and recycled ideas (that contain novel elements), with design fixation occurring only in a minority of cases. 


\begin{tabular}{|l|l|l|l|l|}
\hline Team (No. of ideas) & Fixate & Recycle & Novel & Not relevant \\
\hline $1(9$ ideas $)$ & $0 \%$ & $33 \%$ & $11 \%$ & $56 \%$ \\
\hline $2(10$ ideas $)$ & $57 \%$ & $43 \%$ & $0 \%$ & $0 \%$ \\
\hline $3(7$ ideas) & $14 \%$ & $0 \%$ & $29 \%$ & $57 \%$ \\
\hline $4(9$ ideas) & $22 \%$ & $45 \%$ & $33 \%$ & $0 \%$ \\
\hline $5(7$ ideas $)$ & $0 \%$ & $29 \%$ & $0 \%$ & $71 \%$ \\
\hline $6(6$ ideas) & $0 \%$ & $50 \%$ & $50 \%$ & $0 \%$ \\
\hline $7(5$ ideas $)$ & $0 \%$ & $0 \%$ & $20 \%$ & $80 \%$ \\
\hline $8(8$ ideas $)$ & $12 \%$ & $25 \%$ & $25 \%$ & $38 \%$ \\
\hline Average & $\mathbf{1 3 \%}$ & $\mathbf{2 8 \%}$ & $\mathbf{2 1 \%}$ & $\mathbf{3 8 \%}$ \\
\hline
\end{tabular}

Table 4 - Number of generated ideas that were copied (fixate), recycled or novel for the How construct

Upon closer examination, the most common types of ideas that were recycled were related to the emotions experienced by the living character in relation to the death and remembrance of the dead character as well as particular customs and traditions from the DotD festival. Children of this age may not have had direct experience with death and therefore they may have used the design examples to imagine how the character could be feeling. Furthermore, the majority of the children had not come across the DotD before and were reliant on drawing on the design examples to help them situate their narrative within this context and employ cultural knowledge. The most common idea that was fixated upon by the children was from Design Example 1 when the girl is pulled down into the world of the dead by a flower whilst at her mother's graveside - some teams included this exactly into their narrative whilst other teams used the idea of 'falling', 'being dragged' or entering the world of the dead via a grave. This is a surprising and significant moment in the Design Example 1 narrative that may have remained in the children's memories for longer than other parts of the story and therefore influenced their own ideation process.

\section{Discussion}

Although it is widely acknowledged that the use of design examples during creative ideation can impact both the appropriateness and novelty of the resulting ideas, opinions are mixed on the extent to which the reuse of these design examples is favourable (Hiniker et al., 2017; Kuure et al., 2010; Read et al., 2013a). Our results help to shed light on how this phenomenon occurs during children's ideation. Below we consider the potential methodological implications these findings have for the use of design examples during PD with children. 


\subsection{Appropriateness (relevance and coherence)}

Our results have shown that the relevance of children's ideas across the narrative dimensions was generally quite high. We have seen that one of the most challenging narrative dimensions is the why (narrative motivation). In this respect, the design examples did help inspire the children, which we can observe through the frequent recycling, as well as fixation, of ideas from these examples (discussed in more detail below). Design examples serve not just as inspiration but also can help to scaffold children's understanding (Benton and Johnson, 2014; Khaled and Vasalou, 2014). Within the context of narrative ideation our findings suggest a need for additional facilitation to enable children to use the design examples to appropriately scaffold their ideation for each narrative dimension. To fulfil this need part of the initial stage of the workshop could be dedicated to highlight how these dimensions are identified within the narrative as well as the techniques that are used to communicate them to an audience, promoting the generation of more coherent narratives. Furthermore, the importance and function of these dimensions could be explained to the children through the use of these examples. A question for future research is whether this approach would enable children to move beyond fixation upon exact concrete details of examples to using them as creative inspiration at a more abstract level going beyond previous proposed solutions such simply defining the design task in an ambiguous way (Read et al., 2013a).

We have seen that irrelevant ideas were included in the final narratives calling us to consider how we can structure the design process to remove these before they make it to the final outcome. Tying this back to creativity, having irrelevant ideas is part of the divergent thinking process, and therefore idea irrelevance is not negative. However, these should be filtered out when these ideas are converged to the final narrative, which did not always happen in our case study. Therefore this requires the explicit facilitation of the children's convergent thinking, which in previous work has often been done outside of the design sessions by the adult facilitators (Hiniker et al., 2017; Kelly et al., 2006). Although there has been previous work that provides practical approaches to convergent thinking for children (e.g. the Mixing Ideas technique by (Guha et al., 2004)) there are limited guidelines around how children themselves could decide on the relevant ideas to take forward. Children need to understand why certain ideas might not be relevant, which could be achieved through the use of the design examples alongside convergence criteria based on these examples against which children could evaluate their ideas. In our context in addition to pulling out the necessary narrative dimensions, facilitators could provide justifications for how these example dimensions are relevant to the design task, contrasting the difference between multiple examples to demonstrate different ways an idea could be considered relevant in relation to the design task. 


\subsection{Novelty}

Previous work appears to highlight a gap in children's creative ideation foregrounding a challenge in establishing novel ideas. While some researchers have found children to engage in design fixation (Hiniker et al., 2017; Read et al., 2013a), others have shown a more nuanced perspective on creative ideation facilitated through idea recycling (Kuure et al., 2010). Our findings lend support to the latter view, indicating that there was no pure novelty, but that children drew from their experience of relationships, mixing existing ideas with novel ones reflecting the potential of design examples to foster novelty seen in previous child PD studies (Khaled and Vasalou, 2014). This suggests a process of social learning and creativity rather than design fixation. There was a limited amount of direct copying, but widespread recycling of ideas which highlighted the facilitative role of the design examples on the resulting creative outcome of the design process. One explanation for this extensive use of recycling in this case study may be due in part to the children's lack of experience and familiarity with the design context (both the DotD celebration itself as well as the wider notion of mortality). However, even though the context may have been unfamiliar, children were still able to embed novel aspects into their recycled ideas from their prior experiences such as family relationships and friendship.

All of the teams that were missing dimensions of their narrative had incorporated their own novel ideas, thus in the context of this workshop it appeared the use of design examples helped the other teams to replicate the narrative structure exemplified in the two design examples. Building on the earlier suggestion of deconstructing the design examples to highlight individual narrative dimensions and provide further support for children to weave their ideas for each dimension together, this could enable the generation of novel ideas to be subsequently assembled into a coherent narrative. Furthermore, the process of recycling ideas from the design examples appears to ensure relevance and also invites novelty, so children could be provided strategies for how existing ideas could be adapted novel ways within the narrative. This may also help to reduce the cognitive effort that can increase the likelihood of an overreliance on the design examples (Crilly and Cardoso, 2017).

More novelty was seen in the dialogue and action (how) ideas, where there were some novel methods of communication, despite similarities in the character's motivation (why) to communicate. The how dimension, unlike the other three dimensions, invited multiple ideas so we can more clearly see patterns between novelty and appropriateness within the teams. All teams drew on the design examples to a certain extent, but no team was completely fixated on these, with all teams demonstrating the ability to use a combination of ideas from different sources. This suggests that the concept of fixation and recycling is not binary, even 
if fixation occurs in some aspects of ideation this does not prevent novelty in other aspects, which contradicts Read et al's (2013a) suggestion that fixation (or 'bias') prevents later divergent thinking. We have also seen that children were more likely to fixate or recycle ideas from contexts they are less familiar with and they were more likely to be influenced by significant and memorable parts of the narrative. This supports Purcell and Gero's (1992) claim of influence being related to a lack of familiarity with the design task. Therefore it is important to be aware of which aspects of the design task could be most unfamiliar or less relevant to children's daily lives and ensure that a range of examples are provided to illustrate this so children are not solely influenced by a single design example idea. In addition since the analysis only looked at the final narrative ideas, it is not known what ideas the children discounted. Consequently, it is possible that they generated other novel ideas but rejected these in favour of something closer to the design examples based on the assumption that this represented what the adult facilitators wanted, as highlighted by previous child PD researchers (Hiniker et al., 2017; Read et al., 2013a). This could be mitigated through the additional support for an explicit convergence process suggested earlier.

\section{Conclusion}

Children are increasingly being involved in the technology design process using approaches such as PD, but many researchers have cautioned that this participation can be simply tokenistic (Frauenberger et al., 2015; Read et al., 2013b). Design examples are frequently employed during the ideation process to support children in the generation of creative ideas. However, as these examples influence the outcomes of this process there is a real danger they may restrict the design space to such an extent that children's involvement is little more than tokenistic where their contributions are simply used as a confirmation of the adult designers' initial ideas.

In this paper we have shown that the use of design examples in PD can result in both design fixation and recycling behaviours. The primary findings from our case study include:

- Design examples are key to ascertain relevance to the design task and are thus important to the design process, although the choice and influence of these examples is rarely reflected on in the child PD literature.

- Design examples facilitate novelty through idea recycling and therefore are key to scaffolding creative ideation, supporting Kuure et al.'s (2010) proposal that this can be used as a tool for defining the design space.

- In addition to this, the space is fluid and can move between fixation, recycling and novelty, challenging prior research in this area. 
These findings suggest two overarching implications: (1) taking a more designerly approach to interpretation of children's ideas that is not binary but recognises that novelty manifests within recycled examples; (2) taking a reflexive methodological approach that identifies areas where creativity is particularly undermined due to a stronger tendency toward fixation or lack of relevance/coherence. Within our study the determining factors were lack of familiarity with the design context (leading to more idea fixation), lack of understanding of narrative structure (leading to a lack of idea coherence) and a lack of convergent thinking criterion (leading to less relevant ideas). We therefore propose the following set of recommendations for $\mathrm{CCI}$ researchers and designers looking to use design examples to inspire and guide children's creative idea generation during the PD process:

- When introducing design examples dedicate time to deconstructing them with the children to guide them in abstracting the important and relevant aspects in relation to the design task (i.e. communicating why they were selected as design examples).

- Facilitate the process of convergent thinking by helping children to evaluate their initial ideas against a concrete set of design task criteria to ensure they are taking forward their more appropriate ideas.

- Emphasise the preference for novel ideas (i.e. that you are looking for something that is 'different' to the examples given) and provide strategies for reusing and adding novelty to existing design examples.

- Identify aspects of the design task that children may be less familiar with in advance of the sessions (e.g. through conversations with teachers and/or parents or based on previous experience working with this age group) and ensure that a range of different design examples are presented to provide additional support and inspiration where children may be more reliant on the design examples.

While the focus of the current study was on children, previous PD work focused on adult populations has highlighted similar challenges in creative ideation (Sanders and Stappers, 2008). Thus our recommendations may also be helpful when involving novice adult designers in PD, who would also typically rely more heavily on design examples due to their lack of prior experience with the divergent and convergent thinking processes required to generate their own creative ideas.

In this paper we have discussed how design examples can play a key role in the idea generation process when involving children in PD, with researchers such as Kuure et al. (2010) highlighting how the partial reuse of these can enable more children to participate in this process. The deconstruction of more complex design examples so children can clearly see the ideas that form the overall example and how they might apply this structure to their own 
ideas is one strategy to allow space for the generation of novel, but appropriate ideas. As designers and researchers we must be mindful about how our design example choices may impact upon the design outcomes of this process and how we can effectively exploit this tool to best facilitate children's creative contribution.

\section{References}

Alborzi, H., Druin, A., Montemayor, J., Sherman, L., Taxén, G., Best, J., Hammer, J., Kruskal, A., Lal, A., Schwenn, T.P., Sumida, L., Wagner, R., Hendler, J., 2000. Designing StoryRooms : Interactive Storytelling Spaces for Children, Proceedings of the 3rd conference on Designing interactive systems: processes, practices, methods, and techniques. ACM, pp. 95-104.

Beghetto, R.A., 2005. Does assessment kill student creativity? The educational forum 69, 254-263.

Benton, L., Ashwin, E., Johnson, H., Grawemeyer, B., Brosnan, M., 2011. IDEAS: An interface design experience for the autistic spectrum, Proceedings of the 2011 annual conference on Human factors in computing systems. Association for Computing Machinery (ACM), pp. 1759-1764.

Benton, L., Johnson, H., 2014. Structured approaches to participatory design for children: can targeting the needs of children with autism provide benefits for a broader child population? Instructional Science 42, 47-65.

Bordwell, D., 2008. Poetics of Cinema. Routledge.

Bossen, C., Dindler, C., Iverson, O.S., 2012. Impediments to user gains: experiences from a critical participatory design project, Proceedings of the 12th Participatory Design Conference. ACM Press, Roskilde, Denmark, pp. 31-40.

Branigan, E., 2013. Narrative Comprehension and Film. Taylor \& Francis.

Calleja, G., 2013. Narrative involvement in digital games, Conference proceedings from Foundations of Digital Games. Chania, Crete, Greece.

Cassidy, B., Sim, G., Horton, M., Fitton, D., 2015. Participatory design of wearable augmented reality display elements for children at play, Computer Science and Electronic Engineering Conference (CEEC), pp. 53-58.

Crilly, N., Cardoso, C., 2017. Where next for research on fixation, inspiration and creativity in design? Design Studies 50, 1-38.

Dindler, C., Iversen, O.S., 2007. Fictional Inquiry - design collaboration in a shared narrative space. CoDesign 3, 213-234.

Druin, A., 1999. Cooperative inquiry: developing new technologies for children with children, Proceedings of the SIGCHI conference on Human factors in computing systems. ACM Press, Pittsburgh, USA, pp. 592-599.

Druin, A., 2002. The role of children in the design of new technology. Behaviour and IT 21, 1-25.

Duh, H.B.-1., Lynn, S., Yew, C., Chen, V.H.-h., 2010. A Narrative-Driven Design Approach for Casual Games with Children, Proceedings of the 5th ACM SIGGRAPH Symposium on Video Games. ACM, pp. 19-24.

Farooq, U., Carroll, J.M., Ganoe, C.H., 2005. Supporting creativity in distributed scientific communities, Proceedings of the 2005 international ACM SIGGROUP conference on supporting group work, pp. 217-226.

Frauenberger, C., Good, J., Fitzpatrick, G., Iversen, O.S., 2015. In pursuit of rigour and accountability in participatory design. International journal of human-computer studies 74, 93-106.

Giaccardi, E., Paredes, P., Díaz, P., Alvarado, D., 2012. Embodied Narratives : A Performative CoDesign Technique, Proceedings of the Designing Interactive Systems Conference. ACM, pp. 1-10. Grawemeyer, B., Johnson, H., Brosnan, M., Ashwin, E., Benton, L., 2012. Developing an Embodied Pedagogical Agent With and For Young People with Autism Spectrum Disorder, Proceedings of the 11 th international conference on Intelligent Tutoring Systems. Springer-Verlag, Chania, Crete, Greece, pp. 262-267.

Guha, M.L., Druin, A., Chipman, G., Fails, J.A., Simms, S., Farber, A., 2004. Mixing ideas: a new technique for working with young children as design partners, Proceeding of the 2004 conference on Interaction design and children building a community - IDC '04. ACM, New York, New York, USA, pp. 35-42. 
Hassard, S.T., Blandford, A., Cox, A.L., 2009. Analogies in design decision-making, Proceedings of the 23rd British HCI group annual conference on people and computers: celebrating people and technology. British Computer Society, pp. 140-148.

Herring, S.R., Chang, C.-C., Krantzler, J., Bailey, B.P., 2009. Getting inspired!: understanding how and why examples are used in creative design practice, Proceedings of the SIGCHI conference on Human factors in computing systems, pp. 87-96.

Hiniker, A., Sobel, K., Lee, B., 2017. Co-Designing with Preschoolers Using Fictional Inquiry and Comicboarding, Proceedings of the 2017 CHI Conference on Human Factors in Computing Systems. ACM, pp. 5767-5772.

Hornof, A.J., 2009. Design with Children with Severe Motor Impairments, Proceedings of the SIGCHI conference on Human Factors in Computing Systems. ACM Press, Boston, USA, pp. 2177-2180. Howard, T.J., Culley, S.J., Dekoninck, E., 2008. Describing the creative design process by the integration of engineering design and cognitive psychology literature. Design studies 29, 160-180. Hsieh, H.-F., Shannon, S.E., 2005. Three approaches to qualitative content analysis. Qualitative health research 15, 1277-1288.

Kelly, R.S., Mazzone, E., Horton, M., Read, J.C., 2006. Bluebells: a design method for childrencentred product development, Proceedings of the 4th Nordic conference on Human-computer interaction: changing roles. ACM Press, Oslo, Norway, pp. 361-368.

Khaled, R., Vasalou, A., 2014. Bridging serious games and participatory design. International Journal of Child-Computer Interaction 2, 93-100.

Kuure, L., Halkola, E., Iivari, N., Molin-juustila, T., Box, P.O., 2010. Children Imitate! Appreciating recycling in participatory design with children, Proceedings of the 11th Biennial Participatory Design Conference. ACM, pp. 131-140.

Low, J., Goddard, E., Melser, J., 2009. Generativity and imagination in autism spectrum disorder: Evidence from individual differences in children's impossible entity drawings. British Journal of Developmental Psychology 27, 425-444.

Luck, R., 2007. Learning to talk to users in participatory design situations. Design Studies 28, 217-242. Mazzone, E., Xu, D., Read, J.C., 2007. Design in evaluation: reflections on designing for children's technology, Proc. HCI 2007, pp. 153-156.

Moraveji, N., Li, J., Ding, J., O'Kelley, P., Woolf, S., 2007. Comicboarding: using comics as proxies for participatory design with children, Proceedings of the SIGCHI conference on Human Factors in Computing Systems. ACM Press, San Jose, USA, pp. 1371-1374.

Pentland, A., 2014. Social physics: How good ideas spread-the lessons from a new science. Penguin. Purcell, T.A., Gero, J.S., 1992. Effects of Examples on the Results of a Design Activity. KnowledgeBased Systems 5, 82-91.

Read, J.C., Fitton, D., Horton, M., 2013a. Theatre, playdoh and comic strips: Designing organic user interfaces with young adolescent and teenage participants. Interacting with Computers 25, 183-198. Read, J.C., Fitton, D., Mazzone, E., 2010. Using obstructed theatre with child designers to convey requirements, CHI'10 Extended Abstracts on Human Factors in Computing Systems, pp. 4063-4068. Read, J.C., Horton, M., Sim, G., Gregory, P., Fitton, D., Cassidy, B., 2013b. CHECk: a tool to inform and encourage ethical practice in participatory design with children, CHI '13 Extended Abstracts on Human Factors in Computing Systems. ACM, Paris, France, pp. 187-192.

Runco, M.A., Jaeger, G.J., 2012. The standard definition of creativity. Creativity Research Journal 24, 92-96.

Sanders, E.B.-N., Stappers, P.J., 2008. Co-creation and the new landscapes of design. CoDesign 4, 518.

Sanoff, H., 2007. Special issue on participatory design. Design Studies 28, 213-215.

Schuler, D., Namioka, A., 1993. Participatory Design: Principles and Practices.

Shah, J.J., Smith, S.M., Vargas-Hernandez, N., 2003. Metrics for measuring ideation effectiveness. Design studies 24, 111-134.

Sio, U.N., Kotovsky, K., Cagan, J., 2015. Fixation or inspiration? A meta-analytic review of the role of examples on design processes. Design Studies 39, 70-99.

Sluis-Thiescheffer, W., Bekker, T., Eggen, B., 2007. Comparing early design methods for children, Proceedings of the 6th international conference on Interaction design and children. ACM, pp. 17-24. Smith, S., Ward, T., Schumacher, J., 1993. Constraining effects of examples in a creative generation task. Memory \& Cognition 21, 837-845.

Stemler, S., 2001. An overview of content analysis. Practical assessment, research \& evaluation 7, $137-$ 146.

Sternberg, R.J., Lubart, T.I., 1999. The concept of creativity: Prospects and paradigms. Handbook of creativity $1,3-15$. 
Tan, J.L., Goh, D.H.-L., Ang, R.P., Huan, V.S., 2011. Child-centered interaction in the design of a game for social skills intervention. Computers in Entertainment 9, 1-17.

Vaajakallio, K., Lee, J.-J., Mattelmäki, T., 2009. It has to be a group work!: co-design with children, Proceedings of the 8th international conference on interaction design and children. ACM, pp. 246-249. Vaismoradi, M., Turunen, H., Bondas, T., 2013. Content analysis and thematic analysis: Implications for conducting a qualitative descriptive study. Nursing \& health sciences 15, 398-405.

Varotsis, G., 2015. Screenplay and Narrative Theory: The Screenplectics Model of Complex Narrative Systems. Lexington Books, Lanham, MD.

Vasconcelos, L.A., Crilly, N., 2016. Inspiration and fixation: Questions, methods, findings, and challenges. Design Studies 42, 1-32.

Vernon, P.E., 1989. The nature-nurture problem in creativity, Handbook of creativity. Springer, pp. 93110.

Warr, A., O'Neill, E., 2005. Understanding design as a social creative process, Proceedings of the 5th conference on Creativity \& Cognition. ACM Press, London, UK, pp. 118-127.

Winn, B.M., 2008. The design, play and experience framework. Handbook of research on effective gaming in education, 1010-1024.

Wyse, D., Ferrari, A., 2015. Creativity and education: Comparing the national curricula of the states of the European Union and the United Kingdom, British Educational Research Journal, pp. 30-47. 